\title{
Project
}

\section{Biodiversity and livelihood in land-use gradients in an era of climate change - outline of a Nepal-Swiss research project}

\author{
Christoph Scheidegger ${ }^{1 *}$, Michael P. Nobis ${ }^{1}$, Krishna K. Shrestha ${ }^{2}$ \\ ${ }^{1}$ Swiss Federal Research Institute WSL, Zürcherstr. 111, CH 8903 Birmensdorf, Switzerland \\ ${ }^{2}$ Central Department of Botany, Tribhuvan University, Post Box 26429, Kirtipur, Kathmandu, Nepal
}

\begin{abstract}
The Swiss National Science Foundation has recently granted a project where we propose to study how different levels of land-use intensity (from primeval forests to arable fields) and climate do affect biodiversity on the southern slope of the Nepalese Himalayas. We will investigate replicated land-use gradients at various altitudes in three regions with a different regional climate, and in particular, different levels of seasonal precipitation. Our core study region will be the Manaslu Conservation Area characterized by an oceanic climate and this region will be compared to a hyper-oceanic region in Annapurna Conservation Area and a semi-oceanic region of the Sagarmatha (Everest) region. By using a quasi-experimental landscape approach organisms will be investigated in six valleys covering different precipitation regimes, altitudinal gradients over $1600 \mathrm{~m}$ representing different temperatures, and four land use types ranging from closed forests to open landscapes. These organisms will include plants, lichens, mushrooms, butterflies and birds. Population data of Red Listed mammals (flagship species) will be collected during the project by local authorities. The functional connectivity of forest fragments along land-use and climate gradients will be assessed for two intensively studied species, the epiphytic lichen Lobaria pindarensis and the tree species Taxus wallichiana.
\end{abstract}

\section{Introduction}

There is general agreement among the scientific community that maintenance of natural levels of biodiversity is necessary for proper ecosystem functioning and the provision of sound ecosystem services to humankind (Schulze and Mooney 1994; Sala et al. 2009), constraints on infectious disease (Patz et al. 2005; Vittor et al. 2006), medicinal and genetic resources, and quality of life (Sala et al. 2009). The most important direct driver of biodiversity loss and change in ecosystem services is habitat transformation, particularly from conversion to agriculture. Tropical moist forests are amongst the most diverse ecosystems on earth (UNEP 2001), but are currently experiencing more extensive deforestation and forest degradation than in the rest of the world (Millenium Ecosystem Assessment 2005). However, deforestation is recognized to contribute

*Corresponding author, e-mail address: christoph.scheidegger@wsl.ch with important benefits to society, opening economic opportunities and the availability of a number of ecosystem goods, at least in the short term. Thus, there is a trade-off balance to find between realizing short-term gains in selected ecosystem goods, while potentially degrading ecological function and other ecosystem services in the long term (Foley et al. 2005; Foley et al. 2007). Recent assessments of the ecological impacts of land-use practices have focused on the need to balance the tradeoffs resulting from human actions (Foley et al. 2005; Mille-nium Ecosystem Assessment 2005) where multifunctional systems at the landscape level could probably provide the best scenario (Foley et al. 2005).

\section{Biodiversity in Mountain Environments}

The personal safety and well-being of one fifth, and water supply for almost half of all people depend directly or indirectly on the functional integrity of mountain ecosystems, 
the key component of which is a robust vegetation cover (Körner 2004). Our continuing dependence on organismal diversity within healthy ecosystems is clear. However, much more research is needed to characterize all the species involved and to discover their complex interactions, impacts on humans, and responses to change (Mindell 2009).

As stated by Körner et al. (2006), mountains are inhabited by more species as one would estimate from their land area and have therefore been called "hot spots" of biodiversity (Körner 2004). Biodiversity in mountain environments often shows a mid elevation peak in species richness, i.e. highest numbers or densities of species occur at a certain range of mid elevations, whereas species richness or density declines towards mountain tops or lower altitudes. This effect has been shown worldwide for several mountain ranges and taxa, including vascular plants in Norway (Grytnes 2003), India/the Himalayas (Oommen and Shanker 2005), or Switzerland/the Alps (Wohlgemuth et al. 2008); ants in Colorado, Nevada, and Utah (Sanders 2002); litter invertebrates in Panama (Olson 1994); small mammals in Madagascar (Goodman and Carleton 1996), Philippines (Heaney 2001), Mexico (Sanchez-Cordero 2001), Nevada and Utah (Rickart 2001), or Costa Rica (McCain 2004); or birds in South America (Rahbek 1997), or Colombia/the Andes (Kattan and Franco 2004).

Such peaks in species richness at mid elevations have also been described from Nepal - especially for the southern slope of the Himalayas: Vetaas and Grytnes (2002) found a mid elevational peak for vascular plants and Baniya et al. (2010) presented corresponding results for lichens. As an important finding, richness of endemic species consistently differed from the overall richness patterns. The peak of endemics is shifted to higher altitudes and demonstrates different history and causation behind these biodiversity patterns.

Conventional explanations for the mid elevation peak include:

o Habitat diversity: Habitat diversity in mountains is primarily based on topographical diversity including strong gradients in exposure, steepness of slope, variation of substrate, disturbance and microclimate over short distances. Gravity is the primary force behind this geodiversity (Körner et al. 2006).

o Compression of climatic zones: Due to the elevation range covered, mountains encapsulate several climatic life zones that would otherwise be separated by thousands of kilometres at low elevation (Barthlott et al. 1996). This is linked to the idea that elevational gradients mirror to some extent latitudinal gradients (Stevens 1992). The compression of climatic zones as well as habitat diversity also contributes to a high local diversity by mass effects, when species establish in sites where a self-maintaining population cannot exist (Shmida and Wilson 1985; Grytnes 2003).

o Geometrical constraints: Constraints due to boundaries of species distributions result in greater overlap of species ranges in the middle of sample domains, leading to an emergent mid-domain peak in richness (Colwell and Lees 2000). Because area decreases along the elevational gradient in general, area has to be considered as an additional geometric constraint, and adequate null models have to be applied for the analysis of species richness (Rahbek 1995; Grytnes and Vetaas 2002).

o Historical factors: If the montane zones are both isolated and large enough to allow population persistence and divergence over evolutionary time, they may represent hotspots due to speciation and endemicity (Lomolino 2001). This is amplified by distributional disjunctions and different refugia due to climate change in former times and sympatric speciation along steep environmental gradients. On the other side, mountain species pools should have relatively high extinction rates and low immigration rates, while lower elevational zones with larger areas having greater potential for serving as a target for immigrants (Lomolino 2001). As a results, widely distributed species in general decline monotonically with elevation, whereas mountain species and especially mountain endemics exhibited a midelevation peak (Kattan and Franco 2004). Against this background, montane ecosystems are simply a special case of the island paradigm (MacArthur and Wilson 1967).

However, the causation behind richness patterns may change with spatial scale and grain and a hierarchical view is needed how factors affect biological diversity at different scales (Shmida and Wilson 1985; Mackey and Lindenmayer 
2001; Soberon 2007). While clear and significant results at broader scales are common, the contribution of drivers at local scales remains often unclear. As an example, the distinctive mid elevational peaks of species richness in Nepal (Vetaas and Grytnes 2002; Baniya et al. 2010) derived from compilations of national floras with upper and lower elevation limits. They do not cover local elevation gradients, and thus the transferability to local scales and conditions is largely unknown.

\section{Effects of Habitat Loss and Fragmentation on Populations}

Deforestation and degradation of old-growth forests has the potential to cause catastrophic species extinctions (Groom et al. 2006). Natural habitat has been displaced by human disturbance by at least $50 \%$ of the global land's surface (Hannah et al. 1994; Sanderson et al. 2002; Turner 2002); and it is predicted, that the pressure on land use and habitat conversion will still increase in future (Sala et al. 2000; Tilman et al. 2001). On the other hand, biodiversity in terms of species richness is often linked to high habitat diversity - that itself is often the results of loss and fragmentation of a single or few dominant habitat types.

Increasing biodiversity loss is expected with progressing habitat loss that typically starts with gap formation or perforation of the habitat. At later stages the gaps are getting more extended and numerous and eventually the non-habitat patches become the dominant part in the landscape. As a result, the structural connectivity between the original habitat patches has been broken and depending on the species' ability to move across this mosaic the fragmented landscape gradually ceases to support more and more species.

\section{Effects of Climate Change on Biodiversity}

Networks of protected areas are a most valuable resource for conserving global biodiversity (Bruner et al. 2001). The majority, however, have been established on a static, presentday snapshot of species distributions, greatly increasing their susceptibility to anthropogenic drivers of global change (Gaston et al. 2006). Climate change in particular represents a key potential threat to their future effectiveness (Burns et al. 2003; Hannah et al. 2007). Evidence from the paleo- ecological record of past climate change (Graham and Grimm 1990), together with recent documented changes in species phenology and distributions (Parmesan and Yohe 2003; Jonzen et al. 2006), and modelled simulations of species future range shifts (Erasmus et al. 2002; Huntley et al. 2008), indicate that species responses to projected climatic change over the coming decades could substantially alter present-day patterns of biodiversity (Hole et al. 2009).

One clear effect of climate warming in mountain environments is the upward shift of species distributions (Parmesan and Yohe 2003). Elevational shifts have been found for several taxa including vascular plants, bryophytes, butterflies, or birds (Hickling et al. 2006; Lenoir et al. 2008). For many taxa these dynamics are quite consistent with an upward shift in mean annual isotherms, but species restricted to mountain habitats seems to be more affected (Lenoir et al. 2008). These shifts have not only been found at distributional margins, but also at the spatial core or elevational optimum of species (Lenoir et al. 2008). Additionally, at lower altitudes of mountains the colonization by specialized low-elevation species may fail to compensate for the loss of high-elevation species (Wilson et al. 2007). Thus, climate warming combined with habitat loss and other drivers of biological change may lead to significant losses in biological diversity especially in mountain environments.

Since last few decades, several modeling approaches have been developed to predict the impact of climate change on biodiversity. Results from these models have suggested some alarming consequences of climate change for biodiversity. However, caution may be required in interpreting results, not least because their coarse spatial scales fail to capture topography or "microclimatic buffering”, because they often do not consider the full acclimation capacity of plants and animals (Botkin et al. 2007), often assume equilibrium, or do not distinguish between the realized and fundamental niche of species (Hutchinson 1957) - a concept that has anyway to be rephrased in time of global change (Araujo and Guisan 2006; Soberon 2007). Several recent studies indicate that taking such aspects into consideration can seriously alter the model predictions (Hole et al. 2009; Willis and Bhagwat 2009).

Basic research on ecological responses of high-elevation species to climatic variables is notably lacking in the Greater Himalayas, but it is generally expected that rapid responses by individual species to climate change may disrupt interactions and may include potential ecological cascading effects with secondary extinctions triggered by losses of key 
species in the alpine ecosystems. The endemic-rich Himalayas include many plant species that may not respond successfully to projected rates and magnitude of climate change (Salick et al. 2009; Xu Jianchu et al. 2009).

Varying drivers of biodiversity at different spatial scales are common. While climate is usually the most important factor at global to regional scales land cover including land use is in general a dominant local driver - with combinations at intermediate scales. This holds not only for species richness, but also for functional or trait diversity or other measures of biodiversity. In this regard, different traits like flowering phenology has recently gained increased attention, especially in the context of climate warming. Based on data of the Biodiversity Monitoring of Switzerland Kühn et al. (2009) showed that phenology of vascular plants within assemblages at an intermediate landscape scale are - quite similar to species richness - mainly driven by climate (temperature), followed by substrate type and land cover with forest cover as the most important land-cover type.

Beside the applicability of statistical modeling to reveal and test important covariates of species richness or traits, or to predict such measures of biodiversity in space, these methods can also be used for projections in time based on environmental change scenarios. In a recent publication the Swiss partner analyzed changes in the species richness of neophytes, i.e. non-native plant species introduced to Switzerland since 1500 (Nobis et al. 2009). By using different scenarios for land cover (urban sprawl) and climate (climate warming) we showed that neophyte species richness is basically driven by climatic conditions, and urban areas additionally modulate small-scale differences upon a coarsescale pattern. According to our projections, climate warming will contribute to the future increase in neophyte species richness much more than ongoing urbanization, with highest gains at lower altitude. However, small-scale differences at low altitudes will be strongly affected by urban areas. Again, while the overall diversity pattern is primarily driven by climate conditions, strong small-scale differences at local conditions are controlled by land use.

\section{Consequences of Biodiversity Change for Human Health and Well Being}

The loss of biodiversity by global change, most immediately affects the world's poor, who depend on wild plants, animals and wild habitats for basic goods such as food, shelter and medicines. Because of this link between biodiversity loss and human well-being, conserving and managing ecosystem and species in a sustainable way become more and more important (Millenium Ecosystem Assessment 2005; Fuentes 2008). Himalaya Mountains are rich in medicinal plants and mountain dwellers have long tradition of using these medicinal and aromatic plants for their health care. The great majority of people in the Himalayas rely primarily on herbal medicine. Folk medicine is widely used and the region is home to four of the world's great medical traditions - Ayurveda, Chinese, Tibetan and Unani. Additionally, many people outside the Himalayas use medicines derived from Himalayan plants, generating large-scale trade in certain species.

In highlands of Nepal, collection of these plants from wild for sale in market is an integrative part of mountain peoples' livelihood and has significant share in local household as well as national economy (Olsen and Larsen 2003). Due to socio-economic transformation, urban people rely mostly on modern allopathic medicine but mountain people still use selected medicinal plants and formulations prepared from them. Ethnomedicinal knowledge can provide a lead for this venture (Hamilton 2003; Shrestha et al. 2007).

\section{Research Plan}

\section{OVERALL GOAL AND MAIN OBJECTIVES}

The overall goal of this research collaboration is to identify and analyze how land-use and climate change affect biodiversity in high-elevational landscapes in the Himalayas. We will analyze the consequences of biodiversity change for (1) species richness of plants, mushrooms, lichens, butterflies and birds, the two latter groups being assessed by regional parataxonomists, (2) plant functional groups, (3) rare, endangered and red-listed mammal and bird species (documented by staff of National parks and local parataxonomists), (4) selected ecosystem goods and services including medicinal and aromatic plants, edible fungi and lichens used for incense and spices on the Indian and Nepali markets (Upreti et al. 2005; Scheidegger and Werth 2009).

Besides the expected rise in mean temperature in the Himalayas, climate change leads to more intense rainfall events while the number of rainy days and total amount of precipitation has decreased (Cruz et al. 2007). This will (1) 
Table 1. Study regions.

\begin{tabular}{llll}
\hline Parameters & Sagarmatha & Manasalu & Annapurna \\
\hline Conservation Type & Outside Park & Conservation Area & Conservation Area \\
Location & Eastern Region & Central Region & Western Region \\
Districts & Solukhumbu & Gorkha, Manang, Lamjung & Manang, Mustang, Kaski, Myagdi, Lamjung \\
Major ethnic groups & Sherpa, Rai, Tamang, Newar & Gurung, Thakali, Thakuri, Lama & Gurung, Magar, Thakali, Brahmin, \\
Area (sq.km) & Not applicable & 1663 & 7629 \\
Altitude (m) & $2843-6957$ & $600-8163$ & $790-8091$ \\
$\begin{array}{l}\text { Average Annual } \\
\text { Precipitation (mm) }\end{array}$ & 1000 & 1900 & 3650 \\
\hline
\end{tabular}

have a direct effect on biodiversity because temperature is the main limiting ecological factor in humid mountain regions, and (2) influence the way and intensity how local population will manage their land. Current and future biodiversity change is the combined consequence of climate- and land-use change.

In our project we therefore propose to study how different levels of land-use intensity, from primeval forests to arable fields will affect biodiversity in temperature and precipitation gradients. We will study replicated land-use gradients at various altitudes (temperature gradient) in three regions with different regional climate, i.e. different levels of seasonal precipitation (precipitation gradient). This approach will allow to quantify the effects caused by climate and landuse, respectively, and to provide the necessary scientific data for the development of land-use and conservation strategies for a sustainable use of natural resources in times of climate change. This information will be made available to regional and national stakeholders.

\section{STUDY DESIGN}

Our project will be carried out in three regions covering different precipitation regimes in the southern slope of the Himalayan Mountains in Nepal (Table 1). According to the main objectives the design of this study considers both climate and land use gradients in Nepalese Himalayas and will be carried out at three different spatial levels: (i) between regions, (ii) within regions, and (iii) at local conditions (Fig. 1).

The "between regions level" will enable the comparison of regions with different climates with respect to precipitation. These regions include (1) hyper-oceanic climate in the region around Lumle in Annapurna Conservation Area, (2) oceanic climate in the Manasalu Conservation Area, and (3) semi- oceanic climate in the Sagarmatha region (Everest region). Within each region we will select two independent valleys (sub-drainage basins) as replicates for the region.

The "within region level" will focus on different temperature conditions and therefore considers different altitudes. Because species richness - especially for species endemic to Nepal or Himalayas and at larger scales - is highest in high mountain areas, this study will be carried out in the upper forest zone up to the timber line (about 2400 - $4000 \mathrm{~m}$ a.s.l.). In each region, five localities at different altitudes (around 2400, 2800, 3200, 3600 and $4000 \mathrm{~m}$ a.s.l.) including the highest settlement at or close to the timber line will be investigated. The altitudinal steps between each site will be about $400 \mathrm{~m}$, thus the whole elevational gradient will span about $1600 \mathrm{~m}$ in total.

At the "local level", in each region and at each of the five altitudes two land-use gradients will be established along a contour line with one gradient on each aspect/slope of the valley. Beside different land use, this local level is also designed to compare differences in (micro-)climate within short distances between both sides/slopes of the valleys.

Each land-use gradient will include four different types of land-use:

(1) Natural forest areas with either pristine character or with a low anthropogenic influence that include low levels of tree harvest that does not alter the forest stand structure and tree species composition. In this forest villagers cannot go for one-day round trip collection because of the distance. With natural forest stand (mainly pine forests and mixed broadleaf temperate forests), also the resources include rocks and pastures that have not been grazed or which have been abandoned for more than a decade. Normally forest stands far 

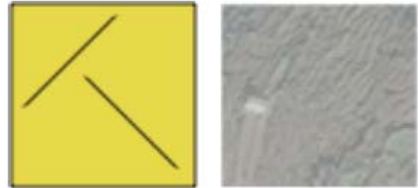

crop fields and gardens
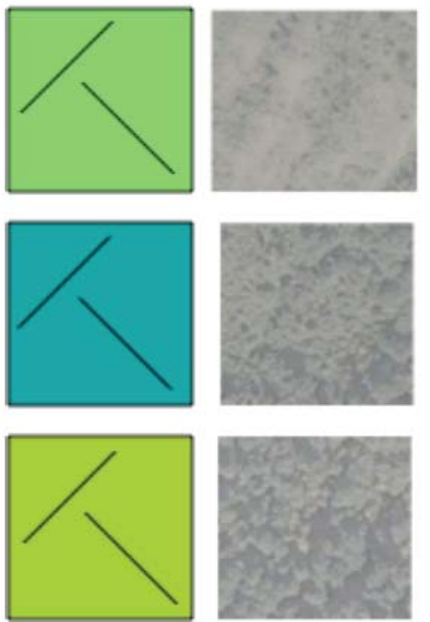

\section{wooded meadows}

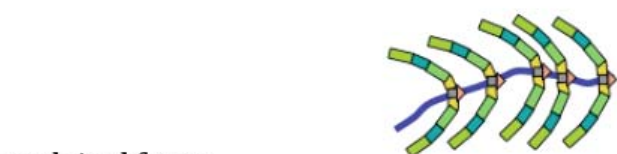

exploited forest

natural forest
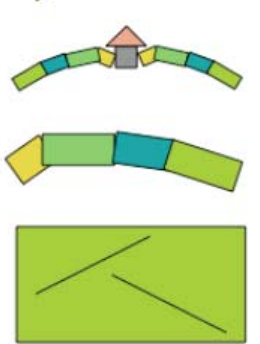

b
3 regions along a precipitation gradient

\section{2 independent valleys per} region

5 localities along altitudinal gradient

\section{2 land-use gradients along contour line (settlement between the two gradients) stratification into 4 land-use types}

random selection of 2 transects within each landuse type

Figure 1. Land-use type with two randomly selected transects (left) and example from satellite (a) and study design to identify and analyze how land-use and climate change affect biodiversity in high-elevational landscapes in the Himalayas (b).

from human settlements are reported to have this kind of forest.

(2) Plantation and exploited forests with average tree age $>20$ years and revealing a relatively closed canopy but with an altered stand structure and tree species composition compared to natural forests, either because of intensive exploitation for agriculture, livestock, and collection of fodder and fuel woods or plantation after intensive domestic or commercial forest management. Due to limited lands suitable for living and farming in and around this type of forest, the land resources are heavily exploited.

(3) Wooded meadows and meadows with less than $20 \%$ tree coverage. Domestic livestock including goats, buffalos, cows, yaks and horses graze or browse the vegetation, which have seen a great impact on resources. Trees are largely treated by various lopping regimes.

(4) Crop fields and gardens are intensively managed, fertilized, sometimes irrigated and yearly ploughed. On slopes fields are often terraced and soil erosion is the main problem. Main crops include maize, wheat, and finger millet, rice, beans, potato, barley, oat and buckwheat. Vegetables are mainly cultivated in gardens in home yards and in close vicinity of the settlements. Similarly, varieties of non-timber forest products (NTFPs) and medicinal and aromatic plants (MAPs) are also cultivated either for commercial purpose or for daily uses.

The land-use gradient will be stratified into the four landuse types along a contour range of $\pm 50 \mathrm{~m}$. In each land-use type two transects will be randomly selected within the contour range. The length of one transect is $50 \mathrm{~m}$. Thus, in total 240 land-use units from 60 land-use gradients from 30 localities will be sampled. The transect method has been widely tested in the Swiss biodiversity monitoring program and is thus applicable also in steep mountain regions. Nevertheless, the protocol will be tested and possibly adapted before the training courses for the PhD students and parataxonomists.

Beside different land use, this local level is also designed to compare differences in (micro-)climate within short 
distances between both sides/slopes of the valleys. For this purpose the orientation of all valleys have to be more or less the same.

\section{WORKPACKAGES}

The project is subdivided into six workpackages (WP). The detailed description of the study areas at the regional and local levels will be carried out in WP 1 . The assessment of biodiversity along the land-use gradients will be carried out in WP2 and in WP 3 local and regional gene flow will be studied for two species in order to assess functional connectivity of the studied areas within and between land-use gradients. Data analyses are assigned to two different work packages: in WP4, all present-day data will be prepared and analyzed, whereas significant effects between biodiversity and environment will be used in WP5 to develop biodiversity scenarios under different future environmental changes. The outcomes of the research project will be summarized and the consequences for sustainable land-use and appropriate conservation measures to mitigate climate change effects in the study region will be discussed with stakeholders and appropriate documentations will be elaborated in WP6.

WP 1: Implementation of the sampling design and site description.

We determine landscape-level structural parameters from satellite images and aerial photographs (if available) with GIS methods across land-use gradients. Land-use types will be classified according to crop systems, disturbance frequency and intensity. Landscape metrics such as patch size, fragmentation and structural connectivity will be calculated for the land-use gradients. Meteorological data (temperature, precipitation, air humidity, photosynthetic active radiation and sun light, wind speed and direction) according to standard protocols will be measured for 12 localities, i.e. the lowest and highest locality in each valley studied. Topsoil temperature (daily average, min and max) will be measured with data loggers for all 240 transects. Canopy disturbance will be classified according to Vetaas (1997), and canopy openness will be assessed for all land cover types by digital, hemispherical photographs (fisheye photographs). This well established method (Anderson 1964; Frazer et al. 2001) is not only suitable for assessing light indirectly and describing canopy structures; in addition, this method enables an excellent documentation of the sites and plots (Nobis and Hunziker 2005). The locations for data-loggers and hemispherical photographs will be directly spatially linked to the species assessment and placed along the same transects as described in the following workpackage. Current Land-use will be described for each site and land-use history of the last 50 years documented based on interviews with the landmanagers. Disturbance intensity, frequency as well as irrigation and fertilizer regime will be noted based on information given by the land-managers. The protocols have been developed in the framework of the project BioAssess (Watt et al. 2007) and will be adapted for this project.

WP 2: Assessment of species diversity.

We will assess species occurrences of selected higher taxa including plants, birds, butterflies, mushrooms and epiphytic lichens. All PhD- and Masters students of the project will contribute to the data collection in the field. Plants and lichens will be assessed during one field visit but mushrooms, birds and mammals need bi-weekly observations during the relevant parts of the year. Bi-weekly observations can best be done by local people that are already associated with national parks or conservation NGO's. In the framework of this project, we will thus involve parataxonomists with sufficient faunistic experience in birds and mammals and train parataxonomists in wild mushrooms. For the biodiversity assessment, higher taxa have been selected because of their low levels of intertaxon correlations, and because the quality of taxa capture and identification is relatively easy and reliable (Watt et al. 2007).

The assessment of the species lists will be carried out with standardized protocols on randomly selected transects of $50 \mathrm{~m}$ within land-use types. In comparison to more compact plot shapes, transect sampling will better consider and compensate for nearby heterogeneity within the community level, i.e. changing species combinations and vegetation structures, which are not the focus of our project. Thus, transect sampling is used to characterize the biodiversity of a given land-use unit as a whole.

This information will be complemented by time-restricted observational data collected on each land-use type. This approach will add information about rare and possibly endangered species that would otherwise be neglected in the transect observation. The amount of time to be spent on each land-use type will be fixed (e.g. 1.5 hours). Based on the experiences from the EU framework project BioAssess and 
the Swiss Biodiversity Monitoring Program (BDM) the biodiversity assessment will be carried out by standardized transect sampling. In each land-use unit two separate transects with a length of $50 \mathrm{~m}$ each will be investigated and sampling will follow a strict protocol. Each species of the selected taxa that occurs within a strip of defined width will be recorded. The width of the strip is $2.5 \mathrm{~m}$ for plants, lichens, mushrooms and butterflies, but $25 \mathrm{~m}$ for birds and mammals. The protocols will be tested for each taxonomic group. Replicates at the levels of transects, land-use units, and land-use gradients will be used to enable the control of data quality.

WP 3: Effects of land use and climate change effects on gene flow.

We investigate how patch size and the spatial isolation and fragmentation of habitats affect dispersal and gene flow of two selected forest-dwelling species with different dispersal potential. One species, Lobaria pindarensis Räsänen requires bark surface of old trees as habitat and depends on a relatively moist forest stand microclimate (Joshi and Awasthi 1982), whereas the second species, Taxus wallichiana Zucc. is a generalist species under the canopy in mountain forests (Polunin and Stainton 1984).

Taxus wallichiana is one of the most important medicinal tree species of the Himalayan region. It is dioecious and wind pollinated, with seed dispersal by animals (Zhang et al. 2009). Recently, microsatellite markers have been developed for Taxus wallichiana (Yang et al. 2009), and Zhang et al. (2009) have investigated effects of forest fragmentation on genetic diversity based on intersimple sequence repeat (ISSR) markers.

Lobaria pindarensis is a foliose lichen species associated with the green algal photobiont Dictyochloropsis reticulata. It has been described from, and is widespread in the Himalayas. It has a similar ecology as L. pulmonaria and according to preliminary fieldwork carried out by the Swiss partner $L$. pindarensis mainly disperses with vegetative propagules, which are rather large. They are presumably splash and wind dispersed and seem to be strongly dispersal limited. The lichen is widely distributed and locally frequent in mountain forests and open woodlands in Nepal (Miehe 1990). Preliminary analyses have shown that 7 photobiont specific microsatellite markers work for $L$. pindarensis (Devkota et al., in prep.). Mycobiont-specific-microsatellite markers are available for L. pulmonaria (Walser et al. 2003; Widmer et al. 2010).
WP 4: Analyses of the present-day biodiversity

This workpackage will statistically describe and test the present-day variation of various biodiversity aspects in Nepalese Himalayas in a multivariate environmental space defined by land use, temperature and precipitation. Besides the distributions of single species, different biodiversity measures including species richness, functional diversity based on species traits as well as beta-diversity (Pielou 1975; Magurran 2004) will be analyzed for all combinations of spatial and environmental levels of the project, i.e. between regions/precipitation, altitudes/temperature, and land-use types including micro-climates.

WP 5: Expected biodiversity change under different climate change and land-use change scenarios.

Based on significant present-day covariation of climate and land use with biodiversity measures found in the previous workpackage, WP5 will investigate expected changes in future biodiversity using climate and land-use change scenarios. We will use IPCC scenarios, representing different sets of assumptions regarding the future development of human activities and corresponding climate trajectories (IPCC 2007). Land-use change scenarios will reflect expected dynamics due to changes in climate and socio-economic drivers for the land use types of our study design. Both climate and land-use scenarios will consider low- and a hi-scenarios representing strong and moderate future changes, respectively. Our presentday data and the environmental scenarios will be linked within a modeling framework by using methods like generalized linear models (GLM; McCullagh and Nelder 1989).

Since our projections in time will be based on presentday covariation in space, this is a classical space-for-time substitution approach that always has to be applied with caution. This holds especially when projections are restricted to changes in a single factor only - as often done with climate warming in the global change debate. However, our sampling design is developed to measure simultaneously the covariation of biodiversity with precipitation, temperature and land use. Furthermore, it is designed to reduce potentially confounding effects between these well known drivers of biodiversity. Thus, we will be able to apply space-for-time substitution in a well defined multivariate environmental space of precipitation, temperature and land use. 
WP 6: Consequences of climate change on land use and biodiversity conservation.

The purpose and outcome of the project will be widely disseminated at local, regional, national and international levels by various means. The objectives and results and relevant issues of the project will be published in the daily newspapers, magazines, national and international journals, booklets and books as well. Moreover, emphasis will be given at community level by organizing public awareness programs, conducting training/workshop programs, etc. The local school students and teachers, mother groups, community-based organizations will be mobilized to disseminate the information. The project information will be effectively and widely disseminated through a project website, jointly run by the collaborating institutions in Nepal and Switzerland.

\section{References}

Anderson M.C. 1964. Studies of woodland light climate. 1. the photographic computation of light conditions. Journal of Ecology 52: 27-41.

Araujo M.B. and Guisan A. 2006. Five (or so) challenges for species distribution modelling. Journal of Biogeography 33(10): 1677-1688.

Baniya C.B., Solhoy T., Gauslaa Y. and Palmer M.W. 2010. The elevation gradient of lichen species richness in Nepal. Lichenologist 42: 83-96.

Barthlott W., Lauer W. and Placke A. 1996. Global distribution of species diversity in vascular plants: towards a world map of phytodiversity. Erdkunde 50/4: 317-327

Botkin D.B., Saxe H., Araujo M.B., Betts R., Bradshaw R.H.W., Cedhagen T., Chesson P., Dawson T.P., Etterson J.R., Faith D.P., Ferrier S., Guisan A., Hansen A.S., Hilbert D.W., Loehle C., Margules C., New M., Sobel M.J. and Stockwell D.R.B. 2007. Forecasting the effects of global warming on biodiversity. Bioscience 57(3): 227-236.

Bruner A.G., Gullison R.E., Rice R.E. and da Fonseca G.A.B. 2001. Effectiveness of parks in protecting tropical biodiversity. Science 291: 125-128.

Burns C.E., Johnston K.M. and Schmitz O.J. 2003. Global climate change and mammalian species diversity in US national parks. Proceeding of National Acadcemy of Science 100: 11474 11477.

Colwell R.K. and Lees D.C. 2000. The mid-domain effect: geometric constraints on the geography of species richness. Trends in Ecology and Evolution 15(2): 70-76.

Cruz R.V., Harasawa H., Lal M., Wu S., Anokhin Y., Punsalmaa B., Honda Y., Jafari M., Li C. and Huu Ninh N. 2007. Asia. Climate Change. In: Impacts, Adaptation and Vulnerability. Contribution of Working Group II to the Fourth Assessment Report of the Intergovernmental Panel on Climate Change (M.L. Parry, O.F. Canziani, J.P. Palutikof, P.J. van der Linden and C.E. Hanson, eds), pp. 469-506. Cambridge University Press, Cambridge, UK.

Erasmus B.F.N., Van Jaarsveld A.S., Chown S.L., Kshatriya M. and Wessels K.J. 2002. Vulnerability of South African animal taxa to climate change. Global Change Biology 8: 679-693.

Foley J.A., Asner G.P., Costa M.H., Coe M.T., DeFries R., Gibbs H.K., Howard E.A., Olson S., Patz J., Ramankutty N. and Snyder P. 2007. Amazonia revealed: forest degradation and loss of ecosystem goods and services in the Amazon Basin. Frontiers in Ecology and the Environment 5(1): 25-32.

Foley J.A., DeFries R., Asner G.P., Barford C., Bonan G., Carpenter S.R., Chapin F.S., Coe M.T., Daily G.C., Gibbs H.K., Helkowski J.H., Holloway T., Howard E.A., Kucharik C.J., Monfreda C., Patz J.A., Prentice I.C., Ramankutty N. and Snyder P.K. 2005. Global consequences of land use. Science 309(5734): 570-574.

Frazer G.W., Fournier R.A., Trofymow J.A. and Hall R.J. 2001. A comparison of digital and film fisheye photography for analysis of forest canopy structure and gap light transmission. Agricultural and Forest Meteorology 109: 249-263.

Fuentes M. 2008. Biological conservation and global poverty. Biotropica 40(2): 139-140.

Gaston K.J., Charman K., Jackson S.F., Armsworth P.R., Bonn A., Briers R.A., Catchpole R., Hopkins J., Kunin W.E., Latham J., Opdam P., Stoneman R., Stroud D.A. and Tratt R. 2006. The ecological effectiveness of protected areas: The United Kingdom. Biological Conservation 132: 76-87.

Goodman S.M. and Carleton M.D. 1996. The rodents of the Reserve Naturelle Integrale d'Andringitra, Madagascar. Zoology 85: 257-283.

Graham R.W. and Grimm E.C. 1990. Effects of global climate change on the patterns of terrestrial biological communities. Trends in Ecology and Evolution 5: 289-292.

Groom M.J., Meffe G.K. and Carroll C.R. 2006. Principles of Conservation Biology. Sinauer Associates, Sunderland, USA.

Grytnes J.A. 2003. Species richness patterns of vascular plants along seven altitudinal transects in Norway. Ecography 26(3): 291-300.

Grytnes J.A. and Vetaas O.R. 2002. Species richness and altitude: a comparison between null models and interpolated plant species richness along the Himalayan altitudinal gradient, Nepal. American Naturalist 159(3): 294-304.

Hamilton A. 2003. Medicinal plants and conservation: issues and approaches. Paper presented to International Plants Conservation Unit, WWF-UK.

Hannah L., Lohse D., Hutchinson C., Carr J. and Lankerani A. 1994. A preliminary inventory of human disturbance of world ecosystems. Ambio 23: 246-250.

Hannah L., Midgley G., Andelman S., Araújo M., Hughes G., Martinez-Meyer E., Pearson R. and Williams P. 2007. Protected area needs in a changing climate. Frontiers in Ecology and the Environment 5(3): 131-138.

Heaney L.R. 2001. Small mammal diversity along elevational gradients in the Philippines: an assessment of patterns and hypotheses. Global Ecology and Biogeography 10(1): 1539.

Hickling R., Roy D.B., Hill J.K., Fox R. and Thomas C.D. 2006. The distributions of a wide range of taxonomic groups are 
expanding polewards. Global Change Biology 12(3): 450455.

Hole D.G., Wills S.G., Pain D.J., Fishpool L.D., Butchart S.H.M., Collingham Y.C., Rahbek C. and Huntley B. 2009. Projected impacts of climate change on a continent-wide protected area network. Ecology Letters 12: 420-431.

Huntley B., Collingham Y.C., Willis S.G. and Green R.E. 2008. Potential impacts of climatic change on European breeding birds. PLoS ONE 3(1): e1439. doi:10.1371/journal.pone.0001439.

Hutchinson G.E. 1957. Population studies - animal ecology and demography - concluding remarks. Cold Spring Harbor Symposia on Quantitative Biology 22: 415-427.

IPCC. 2007. Climate Change 2007: Synthesis Report. Report of the Intergovernmental Panel on Climate Change (IPCC), Geneva, Switzerland.

Jonzen N., Linden A., Ergon T., Knudsen E., Vik J.O., Rubolini D., Piacentini D., Brinch C., Spina F., Karlsson L., Stervander M., Andersson A., Waldenstrom J., Lehikoinen A., Edvardsen E., Solvang R. and Stenseth N.C. 2006. Rapid advance of spring arrival dates in long-distance migratory birds. Science 312: 1959-1961.

Joshi M. and Awasthi D.D. 1982. The lichen family Stictaceae in India and Nepal. Biological Memoirs 7(2): 165-190.

Kattan G.H. and Franco P. 2004. Bird diversity along elevational gradients in the Andes of Colombia: area and mass effects. Global Ecology and Biogeography 13(5): 451-458.

Körner C. 2004. Mountain biodiversity, its causes and function. Ambio, Special Report 13: 11-17.

Körner C., Nakhutrishvili G. and Spehn E.M. 2006. Highelevational land use, biodiversity, and ecosystem functioning. In: Land Use Change and Mountain Biodiversity (E.M. Spehn, M. Liberman and C. Körner, eds.), pp. 3-21. Taylor and Francis, Boca Raton.

Kühn I., Nobis M.P. and Durka W. 2009. Combining spatial and phylogenetic eigenvector filtering in trait analysis. Global Ecology and Biogeography 18(6): 745-758.

Lenoir J., Gegout J.C., Marquet P.A., de Ruffray P. and Brisse H. 2008. A significant upward shift in plant species optimum elevation during the 20th Century. Science 320: 1768-1771.

Lomolino M.V. 2001. Elevation gradients of species-density: historical and prospective views. Global Ecology and Biogeography 10(1): 3-13.

MacArthur R. and Wilson E.O. 1967. The Theory of Island Biogeography.Princeton University Press, Princeton, NJ, USA.

Mackey B.G. and Lindenmayer D.B. 2001. Towards a hierarchical framework for modelling the spatial distribution of animals. Journal of Biogeography 28(9): 1147-1166.

Magurran A.E. 2004. Measuring Biological Diversity. Blackwell, Oxford, UK..

McCain C.M. 2004. The mid-domain effect applied to elevational gradients: species richness of small mammals in Costa Rica. Journal of Biogeography 31(1): 19-31.

McCullagh P. and Nelder JA. 1989. Generalized linear models. Chapman \& Hall, London, UK..

Miehe G. 1990. Langtang Himal. Flora und Vegetation als Klimazeiger und -zeugen im Himalaya. Dissertationes Botanicae, Bd. 158, J. Cramer, Berlin, Stuttgart.
Millenium Ecosystem Assessment. 2005. Ecosystems and Human Well-being: Biodiversity Synthesis. World Resources Institute, Washington, D.C., USA.

Mindell D.P. 2009. Humans need biodiversity. Science 323: 15621563.

Nobis M. and Hunziker U. 2005. Automatic thresholding for hemispherical canopy-photographs based on edge detection. Agricultural and Forest Meteorology 128: 243-250.

Nobis M.P., Jaeger J.A.G. and Zimmermann N.E. 2009. Neophyte species richness at the landscape scale under urban sprawl and climate warming. Diversity and Distributions 15(6): 928-939.

Olsen C.S. and Larsen H.O. 2003. Alpine medicinal plant trade and Himalayan mountain livelihood strategies. The Geographical Journal 169: 243-254.

Olson D.M. 1994. The distribution of leaf-litter invertebrates along a neotropical altitudinal gradient. Journal of Tropical Ecology 10: 129-150.

Oommen M.A. and Shanker K. 2005. Elevational species richness patterns emerge from multiple local mechanisms in Himalayan woody plants. Ecology 86(11): 3039-3047.

Parmesan C. and Yohe G. 2003. A globally coherent fingerprint of climate change impacts across natural systems. Nature 421: 37-42.

Patz J., Confalonieri U.E.C., Amerasinghe F., Chua K.B., Daszak P., Hyatt A.D., Molyneux D., Thomson M., Yameogo L., Malecela-Lazaro M., Vasconcelos P. and Rubio-Palis Y. 2005. Health: ecosystem regulation of infectious diseases. In: Ecosystems and Human Well-Being: Curent State and Trends. Findings of the Condition and Trends Working Group (Millennium Ecosystem Assessment, ed.). Island Press, W. D.C., USA.

Pielou E.C. 1975. Ecological Diversity. John Wiley, NY, USA.

Polunin O. and Stainton A. 1984. Flowers of the Himalaya. Oxford University Press, New Delhi, India.

Rahbek C. 1995. The elevational gradient of species richness a uniform pattern. Ecography 18(2): 200-205.

Rahbek C. 1997. The relationship among area, elevation, and regional species richness in neotropical birds. The American Naturalist 149(5): 875-902.

Rickart E.A. 2001. Elevational diversity gradients, biogeography and the structure of montane mammal communities in the intermountain region of North America. Global Ecology and Biogeography 10(1): 77-100.

Sala O.E., Chapin F.S., Armesto J.J., Berlow E., Bloomfield J., Dirzo R., Huber-Sanwald E., Huenneke L.F., Jackson R.B., Kinzig A., Leemans R., Lodge D.M., Mooney H.A., Oesterheld M., Poff N.L., Sykes M.T., Walker B.H., Walker M. and Wall D.H. 2000. Global biodiversity scenarios for the year 2100. Science 287: 1770-1774.

Sala O.E, Meyerson L.A. and Parmesan C. 2009. Biodiversity Change and Human Health: From Ecosystem Services to Spread of Disease. Island Press, Washington, D.C., USA.

Salick J., Fang Z.D. and Byg A. 2009. Eastern Himalayan alpine plant ecology, Tibetan ethnobotany, and climate change. Global Environmental Change 19: 147-155.

Sanchez-Cordero V. 2001. Elevation gradients of diversity for rodents and bats in Oaxaca, Mexico. Global Ecology and Biogeography 10(1): 63-76. 
Sanders N.J. 2002. Elevational gradients in ant species richness: area, geometry, and Rapoport's rule. Ecography 25(1): 25-32.

Sanderson E., Jaiteh M., Levy M., Redford K., Wannebo A., Woolmer G. 2002. The human footprint and the last of the wild. Bioscience 52: 891-904.

Scheidegger C., Werth S. 2009. Conservation strategies for lichens: insights from population biology. Fungal Biology Reviews 23: 55-66.

Schulze E.D. and Mooney H.A. 1994. Biodiversity and Ecosystem Functioning. Springer, NY, USA.

Shmida A. and Wilson M.V. 1985. Biological Determinants of Species-Diversity. Journal of Biogeography 12(1): 1-20.

Shrestha B.B., Jha P.K. and Gewali M.B. 2007. Ethnomedicinal use and distribution of Aconitum naviculare (Bruhl) Stapf. in upper Manang, Nepal. In: Local Effects of Global Change in the Himalayas: Manang, Nepal (R.P. Chaudhary, T.H. Aase, O.R. Vetaas and Subedi B.P., eds.), pp. 171-181.Tribhuvan University, Kathmandu, Nepal.

Soberon J. 2007. Grinnellian and Eltonian niches and geographic distributions of species. Ecology Letters 10(12): 1115-1123.

Stevens G.C. 1992. The elevational gradient in altitudinal range - an extension of Rapoport latitudinal rule to altitude. The American Naturalist 140(6): 893-911.

Tilman D., Fargione J., Wolff B., D’Antonio C., Dobson A., Howarth R., Schindler D., Schlesinger W., Simberloff D. and Swackhamer D. 2001. Forecasting agriculturally driven global environmental change. Science 292: 281-284.

Turner B. 2002. Toward integrated land-change science: advances in 1.5 decades of sustained international research on land-use and land-cover changes. In: Challenges of a Changing Earth: Proceedings of the Global Change Open Science Conference, Amsterdam, The Netherlands, 10 - 13 July 2001 (W. Steffen, J. Jäger, D. Carson and C. Bradshaw, eds), pp. 21-26. Springer, Berlin, Germany.

UNEP. 2001. Global Biodiversity Outlook. Secretariat of the Convention on Biological Diversity, Montreal, Canada.

Upreti D.K., Divakar P.K. and Nayaka S. 2005. Commercial and ethnic use of lichens in India. Economic Botany 59(3): 269-273.

Vetaas O.R. 1997. The effect of canopy disturbance on species richness in a central Himalayan oak forest. Plant Ecology 132(1): 29-38.

Vetaas O.R. and Grytnes J.A. 2002. Distribution of vascular plant species richness and endemic richness along the Himalayan elevation gradient in Nepal. Global Ecology and Biogeography 11(4): 291-301.
Vittor A.Y., Gilman R.H., Tielsch J., Glass G., Shields T., Lozano W.S., Pinedo-Cancino V. and Patz J.A. 2006. The effect of deforestation on the human-biting rate of Anopheles darlingi, the primary vector of falciparum malaria in the Peruvian Amazon. American Journal of Tropical Medicine and Hygiene 74(1): 3-11.

Walser J.C., Sperisen C., Soliva M. and Scheidegger C. 2003. Fungus-specific microsatellite primers of lichens: application for the assessment of genetic variation on different spatial scales in Lobaria pulmonaria. Fungal Genetics and Biology 40(1): 72-82.

Watt A.D., Bradshaw R.H.W., Young J., Alard D., Bolger T., Chamberlain D., Fernández-González F., Fuller R., Gurrea P., Henle K., Johnson R., Korsós Z., Lavelle P., Niemelä J., Nowicki P., Rebane M., Scheidegger C., Sousa J.P., van Swaay C. and Vanbergen A. 2007. Trends in biodiversity in Europe and the impact of land use change. In: Biodiversity Under Threat (R. Hester and R.M. Harrison, eds.), pp. 135-160. Royal Society of Chemistry, Cambridge, UK.

Widmer I., Grande F.D., Cornejo C. and Scheidegger C. 2010. Highly variable microsatellite markers for the fungal and algal symbionts of the lichen Lobaria pulmonaria and challenges in developing biont-specific molecular markers for fungal associations. Fungal Biology 114(7): 538-544.

Willis K.J. and Bhagwat S.A. 2009. Biodiversity and climate change. Science 326: 806-807.

Wilson R.J., Gutierrez D., Gutierrez J. and Monserrat V.J. 2007. An elevational shift in butterfly species richness and composition accompanying recent climate change. Global Change Biology 13(9): 1873-1887.

Wohlgemuth T., Nobis M.P., Kienast F. and Plattner M. 2008. Modelling vascular plant diversity at the landscape scale using systematic samples. Journal of Biogeography 35(7): 1226-1240.

Xu Jianchu, Grumbine R.E., Shrestha A., Eriksson M., Yang X., Wang Y. and Wilkes A. 2009. The melting Himalayas: cascading effects of climate change on water, biodiversity, and livelihoods. Conservation Biology 23(3): 520-530.

Yang J.B., Li H.T., Li D.Z., Liu J. and Gao L.M. 2009. Isolation and characterization of microsatellite markers in the endangered species Taxus wallichiana using the FIASCO method. Hortscience 44(7): 2043-2045.

Zhang X.M., Gao L.M., Moller M., Li D.Z. 2009. Molecular evidence for fragmentation among populations of Taxus wallichiana var. mairei, a highly endangered conifer in China. Canadian Journal of Forest Research 39(4): 755-764. 